\title{
Economic evidence on identifying clinically actionable findings with whole-genome sequencing: a scoping review
}

\author{
Michael P. Douglas, MS', Uri Ladabaum, MD, MS², \\ Mark J. Pletcher, MD, MPH ${ }^{3}$, Deborah A. Marshall, $\mathrm{PhD}^{4}$ and Kathryn A. Phillips, PhD ${ }^{1,5,6}$
}

\begin{abstract}
The American College of Medical Genetics and Genomics (ACMG) recommends that mutations in 56 genes for 24 conditions are clinically actionable and should be reported as secondary findings after whole-genome sequencing (WGS). Our aim was to identify published economic evaluations of detecting mutations in these genes among the general population or among targeted/high-risk populations and conditions and identify gaps in knowledge. A targeted PubMed search from 1994 through November 2014 was performed, and we included original, English-language articles reporting cost-effectiveness or a cost-to-utility ratio or net benefits/benefit-cost focused on screening (not treatment) for conditions and genes listed by the ACMG. Articles were screened, classified as targeting a high-risk or general population, and abstracted by two reviewers. General population studies were evaluated for actual cost-effectiveness measures (e.g., incremental cost-effectiveness ratios (ICER)), whereas studies of tar-
\end{abstract}

geted populations were evaluated for whether at least one scenario proposed was cost-effective (e.g., ICER of $\leq \$ 100,000$ per life-year or quality-adjusted life-year gained). A total of 607 studies were identified, and 32 relevant studies were included. Identified studies addressed fewer than one-third ( 7 of $24 ; 29 \%$ ) of the ACMG conditions. The cost-effectiveness of screening in the general population was examined for only 2 of 24 conditions (8\%). The cost-effectiveness of most genetic findings that the ACMG recommends for return has not been evaluated in economic studies or in the context of screening in the general population. The individual studies do not directly address the cost-effectiveness of WGS.

Key Words: AMCG; economics; incidental findings; review; wholegenome sequencing

Genet Med advance online publication 21 May 2015

\section{INTRODUCTION}

Whole-genome sequencing (WGS) tests are being offered selectively in clinical care and are expected to become more widely used in the future. The American College of Medical Genetics and Genomics (ACMG) released recommendations that specify which secondary findings (SFs) from WGS should be returned to patients. ${ }^{1}$ These recommendations identify 56 genes associated with 24 conditions in which mutations are considered clinically actionable (e.g., treatment or behavior modification that leads to improved health outcomes) (see the definitions in Box 1).

The ACMG made the recommendation to return certain SFs based on an established benefit of clinical utility, and all of the genes included have clinically available tests. ${ }^{1-4}$ However, when the full implications of finding and reporting SFs found with WGS are assessed, the full range of benefits, risks, and costs must be considered. The cost-effectiveness of returning SFs from WGS in the general population or in specific targeted/high-risk population clinical scenarios has not been assessed. Our aim was to identify published economic evaluations of detecting mutations in the 56 genes associated with the 24 conditions that are considered clinically actionable by the ACMG among the general population or in targeted/high-risk populations to identify available economic evidence and gaps in knowledge. Our results inform the costs/benefits of genetic testing for these conditions in both targeted populations and general populations, which may occur as WGS enters clinical care more broadly.

\section{MATERIALS AND METHODS}

\section{Search strategy}

We identified economic evaluations for screening for all conditions and respective genes defined on the ACMG's list of returnable results. ${ }^{1}$ We conducted a targeted search of PubMed for English-language articles of cost-effectiveness, cost-utility, or cost-benefit analyses that specifically addressed the conditions and genes of interest and published from 1994 through November 2014. We limited the search to the past 20 years because the majority of all economic analysis of genetic testing has been done during this time frame, and we used Medical Subject Headings (MeSHs) and keywords to limit the studies to economic analyses and the disease or condition found in the ACMG's list of returnable results. ${ }^{1}$ The search strategy used the following terms:

\footnotetext{
${ }^{1}$ Department of Clinical Pharmacy, Center for Translational and Policy Research on Personalized Medicine (TRANSPERS), University of California San Francisco, San Francisco, California, USA; ${ }^{2}$ Division of Gastroenterology and Hepatology, Department of Medicine, Stanford University School of Medicine, San Francisco, California, USA; ${ }^{3}$ Department of Epidemiology and Biostatistics, University of California San Francisco, San Francisco, California, USA; ${ }^{4}$ Department of Community Health Sciences, Cumming School of Medicine, O'Brien Institute for Public Health, University of Calgary, Calgary, Alberta, Canada; ${ }^{5}$ Philip R. Lee Institute for Health Policy, University of California San Francisco, San Francisco, California, USA; ${ }^{6}$ Helen Diller Family Comprehensive Cancer Center, University of California San Francisco, San Francisco, California, USA.Correspondence: Kathryn A. Phillips (PhillipsK@pharmacy.ucsf.edu)
} 
- Disease or condition-MeSH terms and key words for each. The MeSH term was limited further using the genetics or diagnosis subheading for selected conditions (see Supplementary Appendix A online for specific terms used).

- Cost-effectiveness-“Cost-Benefit Analysis" (MeSH) and "Cost-effectiveness" (key word)

For conditions (e.g., Lynch syndrome and hereditary breast ovarian cancer syndrome) that returned a large number of results, we limited the search by adding the specific terms for the relevant gene(s), using MeSH terms, when available, or key words (e.g., MSH1, BRCA1, or BRCA2). We combined the results of these searches and validated our search, as described below. We augmented our search strategies for economic evaluations related to genetic screening for the disease/conditions and genes on the ACMG list by reviewing references in the Tufts Center for the Evaluation of Value and Risk in Health Cost-Effectiveness Analysis Registry (CEAR) database ${ }^{5,6}$ and in recently published cost-effectiveness and cost-utility studies.?

\section{Article selection}

Titles and abstracts were screened by two independent reviewers according to prespecified inclusion and exclusion criteria, and the full text of relevant articles were retrieved. Disagreements were resolved through discussion and referral to a third reviewer, if necessary. The article inclusion criteria were original articles only, focus on one of the conditions and genes listed in the ACMG list, English language only, provide a measure of relative economic value defined as a cost-effectiveness or cost-to-utility ratio or net benefits/benefit-to-cost ratio, and an economic evaluation screening for the gene, not a treatment. Article exclusion criteria were reviews, editorials, or methods articles and studies solely of "costs." We screened all full-text articles to identify those that included at least one analysis of

Box 1 Defining screening, testing, and reporting on clinically actionable conditions

- Screening is the use of genetic methods, including sequencing, to determine the presence of a genetic-based condition/gene/ variant in a general population (e.g., population screening and returning SFs-all returned results would be considered SFs).

- Testing is the use of genetic methods, including sequencing, to determine the presence of a condition/gene/variant in when a clinical indication is present (e.g., Lynch syndrome testing in high-risk individuals and returning SFs).

- Condition is the disease, syndrome, or other known susceptibility (e.g., 24 conditions outlined in American College of Medical Genetics and Genomics recommendations; Lynch syndrome).

- Clinically actionable is the ability to administer treatment or behavior modification that leads to improved health outcomes (e.g., BRCA1/2 mutations are clinically actionable to reduce breast cancer risk).SF, secondary findings. general population screening (or opportunistic screening of a general population) and those that included only analyses of targeted/high-risk population screening.

\section{Data extraction}

For each included study, two reviewers independently extracted relevant data and study details. Basic article details including population demographics and cost-effectiveness data-specific versus general population studied, incremental cost-effectiveness ratios (ICERs), and author conclusionswere abstracted (see Supplementary Appendix C online). Discrepancies were resolved through discussion.

We defined "cost-effective" as an ICER $\leq \$ 100,000$ per life-year or quality-adjusted life-year (QALY) gained. ${ }^{8,9}$ Using this definition, we determined whether at least one clinical scenario per targeted population study was "cost-effective" for screening for the condition of interest. We assumed testing in a general population scenario to mean the population tested was not limited by other risk factors (e.g., increased risk of the condition because of family history) and a targeted population scenario to mean the population tested was limited by outside factors (e.g., family history of the condition, other clinical factors suggestive of the condition).

\section{Evaluation of methodological quality}

We used the "quality rating" assigned by trained coders from the Tufts CEAR to examine the methodological quality of our included studies that were found in Tufts CEAR. ${ }^{5}$

\section{Studies identified}

\section{RESULTS}

Our search yielded 607 candidate articles, of which 56 remained after title/abstract review, and 32 remained after full-text review $^{10-41}$ (Figure 1) (a complete list of studies can be found in Supplementary Appendix B online).

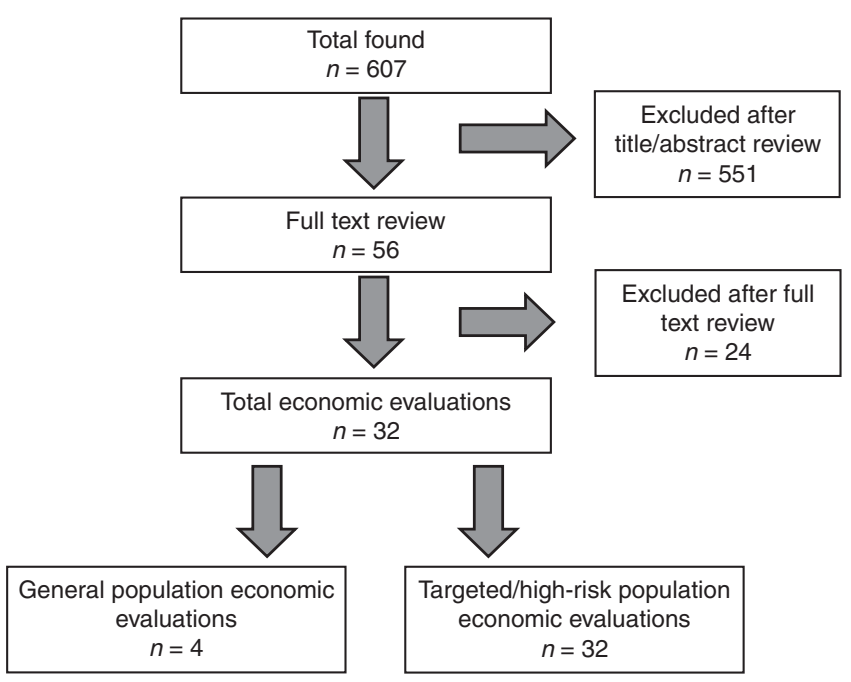

Figure 1 Preferred Reporting Items for Systematic Reviews and Meta-Analyses (PRISMA) diagram of included and excluded studies. 
Table 1 Summary of articles found and cost-effectiveness analyses (CEAs) identified for each condition defined on the American College of Medical Genetics and Genomics list of secondary findings

\begin{tabular}{|c|c|c|c|c|c|c|}
\hline & \multirow[b]{2}{*}{ Condition } & \multirow[b]{2}{*}{$\begin{array}{l}\text { Condition } \\
\text { prevalence }^{\text {a }}\end{array}$} & \multirow[b]{2}{*}{ Genes } & \multicolumn{3}{|c|}{ CEAS } \\
\hline & & & & Total (n) & $\begin{array}{c}\text { Including both } \\
\text { high-risk and general } \\
\text { populations } \\
\text { (general population } \\
\text { testing: \# favorable } \\
\text { (\# total)) }\end{array}$ & $\begin{array}{c}\text { Focused only on } \\
\text { high-risk population } \\
\text { (high risk } \\
\text { population testing: } \\
\text { \# favorablec/ } \\
\text { (\# total)) }\end{array}$ \\
\hline 1 & Lynch syndrome & Common & MLH1, MSH2, MSH6, PMS2 & 14 & $2(0)$ & $12(12)$ \\
\hline 2 & $\begin{array}{l}\text { Hereditary breast and ovarian } \\
\text { cancers }\end{array}$ & Common & $B R C A 1, B R C A 2$ & 6 & 0 & $6(6)$ \\
\hline 3 & Familial hypercholesterolemia & Common & $\angle D L R, A P O B, P C S K 9$ & 6 & $2(2)$ & $4(4)$ \\
\hline 4 & RWS types 1, 2, and 3, BS & $\begin{array}{l}\text { Rare (RWS) } \\
\text { Rare (BS) }\end{array}$ & KCNQ1, KCNH2, SCN5A & 2 & 0 & $2(2)$ \\
\hline 5 & $H C, D C$ & $\begin{array}{l}\text { Common (HC) } \\
\text { Common (DC) }\end{array}$ & $\begin{array}{l}\text { MYBPC3, MYH7, TNNT2, TNNI3, } \\
\text { TPM1, MYL3, ACTC1, PRKAG2, } \\
\text { GLA, MYL2, LMNA }\end{array}$ & 2 & 0 & $2(2)$ \\
\hline 7 & $\begin{array}{l}\text { Multiple endocrine neoplasia } \\
\text { type } 2\end{array}$ & Extremely rare & $R E T$ & 1 & 0 & $1(1)$ \\
\hline 8 & $\begin{array}{l}\text { Catecholaminergic } \\
\text { polymorphic ventricular } \\
\text { tachycardia }\end{array}$ & Rare & $R Y R 2$ & 0 & 0 & 0 \\
\hline 9 & $\begin{array}{l}\text { Familial adenomatous } \\
\text { polyposis }\end{array}$ & $\begin{array}{l}\text { Rare to extremely } \\
\text { rare }\end{array}$ & $A P C$ & 0 & 0 & 0 \\
\hline 10 & Von Hippel-Lindau syndrome & Extremely rare & $V H L$ & 0 & 0 & 0 \\
\hline 11 & Li-Fraumeni syndrome & Rare & TP53 & 0 & 0 & 0 \\
\hline 17 & $\begin{array}{l}\text { Hereditary paraganglioma- } \\
\text { pheochromocytoma syndrome }\end{array}$ & $\begin{array}{l}\text { Extremely rare } \\
\text { Extremely rare }\end{array}$ & $S D H D, S D H A F 2, S D H C, S D H B$ & 0 & 0 & 0 \\
\hline 18 & Tuberous sclerosis complex & Rare & TSC1, TSC2 & 0 & 0 & 0 \\
\hline 19 & WT1-related Wilms tumor & Rare & WT1 & 0 & 0 & 0 \\
\hline 20 & Neurofibromatosis type 2 & Extremely rare & NF2 & 0 & 0 & 0 \\
\hline 21 & EDS—vascular type & Rare & COL3A1 & 0 & 0 & 0 \\
\hline 22 & MS, LDS, and FTAAD & $\begin{array}{l}\text { Rare (MS) } \\
\text { Unknown (LDS) } \\
\text { Unknown (FTAAD) }\end{array}$ & $\begin{array}{l}\text { FBN1, TGFBR1, TGFBR2, } \\
\text { SMAD3, ACTA2, MYLK, MYH11 }\end{array}$ & 0 & 0 & 0 \\
\hline 23 & $\begin{array}{l}\text { Arrhythmogenic right ventricular } \\
\text { cardiomyopathy }\end{array}$ & Common & $\begin{array}{l}\text { PKP2, DSP, DSC2 TMEM43, } \\
\text { DSG2 }\end{array}$ & 0 & 0 & 0 \\
\hline 24 & $\begin{array}{l}\text { Malignant hyperthermia } \\
\text { susceptibility }\end{array}$ & Extremely rare & RYR1, CACNA1S & 0 & 0 & 0 \\
\hline Tota & & & & 32 & 4 & 28 \\
\hline
\end{tabular}

BS, Brugada syndrome; DC, dilated cardiomyopathy; EDS, Ehlers Danlos syndrome; FTAAD, familial thoracic aortic aneurysm dissection; HC, hypertrophic cardiomyopathy; LDS, Loeys-Dietz syndrome; MS, Marfan syndrome; RWS, Romano-Ward long QT syndrome.

Shaded cells indicate conditions for which economic evaluations were found.

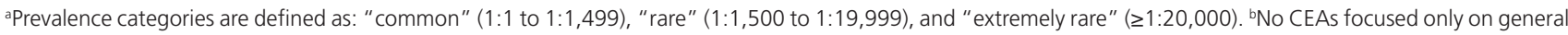
populations. 'Favorable $=$ Study presented at least one scenario where at least one testing scenario was cost-effective (<\$100,000/quality-adjusted life-year or life-year). 


\section{Populations, conditions, and genes examined}

We found cost-effectiveness analyses (CEAs) for only a fraction (7 of 24; 29\%) of all conditions and genes on the ACMG list (Table 1). Only 4 of 32 studies contained analyses for genetic screening in a general population: familial hypercholesterolemia and Lynch syndrome ( 2 of 24 conditions on the ACMG list, or 8\%) (Table 1), whereas all studies included analyses of high-risk or targeted populations (Table 1). Most articles $(n=14)$ focused on Lynch syndrome (genes MLH1, MSH2, MSH6, and PMS2), hereditary breast ovarian cancer syndrome (genes BRCA1 and $B R C A 2 ; n=6$ ), and familial hypercholesterolemia (genes $L D L R$, $A P O B$, and PCSK9; $(n=6)$ (Table 1). The remaining studies $(n=6)$ addressed MYH-associated polyposis (gene MUTYH) multiple endocrine neoplasia type 2 (gene RET), hypertrophic cardiomyopathy and dilated cardiomyopathy (genes MYBPC3, MYH7, TNNT2, TNNI3, TPM1, MYL3, ACTC1, PRKAG2, GLA, MYL2, and LMNA), and Romano-Ward long QT syndrome types 1, 2, and 3 and Brugada syndrome (genes KCNQ1, KCNH2, and SCN5A) (Table 1).

\section{Cost-effectiveness of screening in the general population}

The four CEAs that examined general population screening included several different analyses for familial hypercholesterolemia (six analyses) and Lynch syndrome (three analyses examining no risk stratification before genetic testing) $)^{11,22,23,40}$ (Table 2).

Two analyses by Marks et al. ${ }^{22,23}$ found screening for familial hypercholesterolemia at 16 years of age to be cost-effective in the general population (i.e., mutation prevalence was assumed to reflect the prevalence among the general population) (Table 2).
Furthermore, these same studies found screening for familial hypercholesterolemia between the ages of 16 and 55 in the general population, or opportunistically in primary care, borderline cost-effective (\$104,502-\$125,200/QALY gained) (Table 2).22,23

Both Dinh et al. ${ }^{11}$ and Snowsill et al. ${ }^{40}$ found that general population screening with up-front germ-line testing for Lynch syndrome was not cost-effective (ICER values ranged from nearly $\$ 129,852$ to $>\$ 7$ million per life-year or QALY gained) (Table 2). However, Dinh et al. found that when the risk thresholds for genetic testing were set to 5 and $10 \%$ (a targeted/high-risk population evaluation), the ICERs fell below $\$ 50,000$ per QALY gained.

\section{Cost-effectiveness of screening in targeted/high-risk populations}

For seven conditions, the cost-effectiveness of genetic testing was examined in at least one high-risk or targeted clinical scenario. All of these CEAs found genetic testing to be cost-effective in at least one high-risk or targeted clinical scenario (Table 1; Supplementary Appendix B online).

\section{Evaluation of methodological quality}

Although sample sizes were too small to examine in detail the quality of the methods used, we were able to estimate the methodological quality of seven of the included studies using data from the Tufts CEAR. We calculated a mean quality score of 4.5 for the included studies (range: 3.5-6; scale of 1-7), which was equivalent to the mean score (4.5) for all studies in the CEAR $(N=4,007)$.

Table 2 Details of economic evaluations of the general population

\begin{tabular}{|c|c|c|c|c|}
\hline Condition & Gene(s) & Population & ICER $^{a}$ & Key Conclusion from Articles \\
\hline \multirow[t]{3}{*}{$\begin{array}{l}\text { Familial } \\
\text { hypercholesterolemia }\end{array}$} & \multirow[t]{3}{*}{$\begin{array}{l}\angle D L R \\
A P O B \\
P S C K 9\end{array}$} & $\begin{array}{l}\text { General population } \\
\text { (at } 16 \text { years old) }\end{array}$ & $\begin{array}{l}\$ 22,154 \text { (cost/LY gained) })^{22} \\
\$ 23,805 \text { (cost/LY gained) }\end{array}$ & $\begin{array}{l}\text { "When targeted on the young ( } 16 \text { year old school children), } \\
\text { universal screening also appears relatively cost-effective. } \\
\text { However, screening is less cost effective in } 16-55 \text { year olds } \\
\text { with the least cost-effective in men aged over } 35 \text { years. This is } \\
\text { because the gains in life expectancy for these individuals are } \\
\text { small." } 22\end{array}$ \\
\hline & & $\begin{array}{l}\text { Opportunistic } \\
\text { screening } \\
\text { (16-55 years who visit } \\
\text { their GP) }\end{array}$ & $\begin{array}{l}\$ 104,502(\text { cost/LY gained) })^{22} \\
\$ 112,287 \text { (cost/LY gained) }\end{array}$ & \multirow[t]{2}{*}{$\begin{array}{l}\text { "Screening family members of people with familial } \\
\text { hypercholesterolemia is the most cost effective option for } \\
\text { detecting cases across the whole population." } 23\end{array}$} \\
\hline & & $\begin{array}{l}\text { General population } \\
\text { (16-55 years old })\end{array}$ & $\begin{array}{l}\$ 116,200{\text { (cost/LY gained) })^{22}} ; \\
\$ 125,200 \text { (cost/LY gained) }^{23}\end{array}$ & \\
\hline \multirow[t]{3}{*}{ Lynch syndrome } & \multirow[t]{3}{*}{$\begin{array}{l}\text { MLH1, } \\
\text { MSH2, } \\
\text { MSH6, } \\
\text { PMS2 }\end{array}$} & $\begin{array}{l}\text { General population } \\
\text { (20 years old, no risk) }\end{array}$ & 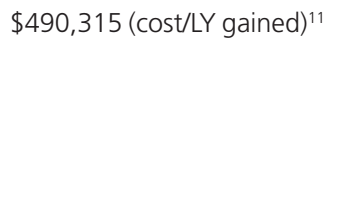 & $\begin{array}{l}\text { "Universal screening offered the greatest benefit in clinical } \\
\text { outcomes, although it did so at the least attractive cost- } \\
\text { effective ness ratios. However, as the risk threshold for genetic } \\
\text { testing was set to } 5.0 \% \text { and } 10 \% \text { (non-universal screening), } \\
\text { the cost-effectiveness values fell below the benchmark of } \\
\$ 50,000 \text { per QALY." }\end{array}$ \\
\hline & & $\begin{array}{l}\text { General population } \\
\text { ( } 25 \text { years old, no risk) }\end{array}$ & $\$ 7,008,872$ (cost/LY gained) ${ }^{11}$ & \multirow{2}{*}{$\begin{array}{l}\text { "Results suggest that reflex testing for LS in newly diagnosed } \\
\text { CRC patients aged }<50 \text { years is cost-effective. Such testing may } \\
\text { also be cost-effective in newly diagnosed CRC patients aged } \\
<60 \text { or }<70 \text { years." } 40\end{array}$} \\
\hline & & $\begin{array}{l}\text { General population } \\
\text { (no risk) }\end{array}$ & $\$ 129,852$ (cost/LY gained) $)^{40}$ & \\
\hline
\end{tabular}

CRC, colorectal cancer; GP, general practitioner; ICER, incremental cost-effectiveness ratio; LS, Lynch syndrome; LY, life-year; QALY, quality-adjusted life-year. a CERs from Marks et al. ${ }^{22,23}$ and Snowsill et al. ${ }^{40}$ were reported in British pounds. They were converted to US dollars based on year-end (31 December) conversion rates: 0.66 (2000), 0.62 (2002), $0.64(2014)$. 


\section{DISCUSSION}

We found very few (7 of 24; 29\%) published health economic evaluations of screening for clinically actionable gene variants among the conditions and genes for which the ACMG recommends returning secondary findings to patients. For the conditions and genes that have been formally evaluated, most studies have focused on targeted/high-risk populations or populations with a high prevalence (i.e., <1:1,500) (Table 1). Our findings suggest that substantial additional data and analyses are required to evaluate fully the benefits, risks, and costs of return of these secondary findings to patients.

The few CEAs that addressed testing for specific genes in the general population suggest that such testing in low-prevalence populations may not be cost-effective (Table 2). With WGS, however, it must be appreciated that a relatively low testing cost may be incurred to obtain information for multiple conditions. If most of the cost incurred from screening is from the test itself rather than the follow-up treatment and health-care utilization, then WGS-enabled screening may improve cost-effectiveness. To illustrate, several models have found that screening for familial hypercholesterolemia in some general populations (i.e., at 16 years), but not in others, may be cost-effective. ${ }^{22,23}$ Testing for this condition in high-risk populations (family members of persons with clinical diagnosis or genetic mutations) using a case-finding/cascade screening approach usually represents the most cost-effective (lowest ICER) application of the screening technology. ${ }^{22,23,25,34,37,41}$ Furthermore, in the case of general population screening for familial hypercholesterolemia, the clinical utility of the genetic test compared with a standard cholesterol test to evaluate an individual patient's possible need for lipidlowering drugs (e.g., statins) may be the more cost-effective approach considering the clinical care pathway would certainly require a cholesterol test before statin use anyway. In Lynch syndrome models demonstrate that general population screening of non-risk-stratified individuals with traditional gene sequencing methods is not cost-effective. ${ }^{11,40}$ When a risk threshold for genetic testing was set to 5 and $10 \%$ (nonuniversal screening), the ICER values fell below the common benchmark threshold of $\$ 50,000$ per QALY gained. ${ }^{11}$ We found no CEAs of BRCA1/2 screening in the general population.

In all of the CEAs included we found at least one high-risk or targeted population screening scenario in which screening was suggested to be cost-effective. ${ }^{10-41}$ Whether substituting WGS (with its yield of SFs) instead of condition-specific targeted testing in these scenarios would improve clinical effectiveness and/or cost-effectiveness remains unclear. However, it is important to consider that lowering WGS costs may affect the cost-effectiveness of using single-gene tests. For example, three of the four general population studies included in our study included sensitivity analyses of the test cost, and in all three cases the cost-effectiveness was relatively more sensitive to test cost compared with other variables. ${ }^{11,22,40}$ In one case a $50 \%$ decrease in test cost resulted in a $35 \%$ reduction of the ICER value for universal screening ( $\$ 14,400$ vs. $\$ 22,154$ cost/ life year gained). ${ }^{22}$ Furthermore, the proportion of the total cost per life year gained that was attributable to the test cost ranged from 0.7 to $6.7 \%\left(\$ 3,495 / \$ 490,315^{11} ; \$ 2,500 / \$ 129,852^{40}\right.$; $\$ 1,492 / \$ 22,154^{22}$; and $\$ 1,603 / 23,805$ (ref. 23)).

\section{Limitations}

We searched only PubMed and thus we may have missed articles not indexed in PubMed, but we expect that this would be rare, and we supplemented our search findings with other databases and key articles. Because we found few relevant CEAs addressing general population screening, these results should be considered only suggestive of what might be found with a larger sample. The individual analyses that we identified do not directly address the cost-effectiveness of WGS, and sequencing of multiple genes at once will have a different range of effects and a different ICER than screening for only one condition.

\section{Conclusions and future research}

It would be useful to have more economic analyses of the conditions and genes on the ACMG list among the general population or high-risk populations. CEAs that examine WGS in populations at high risk for specific conditions, in which the primary aim is to examine the genes associated with this condition but where SFs in other genes also are reported to patients, would be highly informative. Comparisons of WGS versus existing methods, including the use of gene panels, would be of great interest. Furthermore, one must consider how to integrate the economic evaluation of multiple or all of these conditions and the impact of jointly considering these genes/conditions on the cost-effectiveness of WGS. ${ }^{42,43}$ For example, the use of existing CEA results (e.g., QALYs, ICERs) in the development of future CEA models for multiple conditions may not be appropriate data inputs. It is possible that WGS may be more cost-effective than screening for individual conditions/genes because one is screening for multiple diseases. However, WGS may result in a higher number of false-positives that generate further tests/ costs, thus negatively affecting the cost-effectiveness.

In summary, the cost-effectiveness of screening for most of the conditions and genes on the ACGM actionable list remains undefined. Furthermore, the clinical and economic consequences that may follow ascertainment of findings for conditions and genes on the ACGM list have not been explored. When considering the full range of effects that WGS may have in the general population, it will be necessary to integrate the clinical and economic effects stemming from identifying clinically actionable findings, findings with unclear implications for management, and findings of unknown significance across a large number of clinical conditions and associated genes.

\section{SUPPLEMENTARY MATERIAL}

Supplementary material is linked to the online version of the paper at http://www.nature.com/gim

\section{ACKNOWLEDGMENTS}

This study was funded by grants from the National Human Genome Research Institute (R01 HG007063) and the University of 
California San Francisco Mount Zion Health Fund and Helen Diller Family Comprehensive Cancer Center (5P30CA082013-15). The authors thank Alycia Hatashima and Anna Oh for their assistance in screening articles and abstracting data for this study.

\section{DISCLOSURE}

K.A.P. has received honoraria for serving on a scientific advisory panel for Illumina and for a speaking engagement for Life Technologies. Disclosures have been reviewed by the University of California, San Francisco. D.A.M. receives support as an ad hoc consultant in health economics for Optum Insight. The other authors declare no conflict of interest.

\section{REFERENCES}

1. Green RC, Berg JS, Grody WW, et al.; American College of Medical Genetics and Genomics. ACMG recommendations for reporting of incidental findings in clinical exome and genome sequencing. Genet Med 2013;15:565-574.

2. Allyse M, Michie M. Not-so-incidental findings: the ACMG recommendations on the reporting of incidental findings in clinical whole genome and whole exome sequencing. Trends Biotechno/ 2013;31:439-441.

3. National Center for Biotechnology Information Genetic Testing Registry. http:// www.ncbi.nlm.nih.gov/gtr/. Accessed 20 June 2014.

4. GeneTests. http://genetests.org/. Accessed 20 June 2014

5. Neumann PJ, Greenberg D, Olchanski NV, Stone PW, Rosen AB. Growth and quality of the cost-utility literature, 1976-2001. Value Health 2005;8:3-9.

6. Tufts Cost-Effectiveness Analysis Registry. 2013. http://www.cearegistry.org. Accessed 15 October 2014.

7. Hatz MH, Schremser K, Rogowski WH. Is individualized medicine more costeffective? A systematic review. Pharmacoeconomics 2014;32:443-455.

8. Weinstein MC. How much are Americans willing to pay for a quality-adjusted life year? Med Care 2008;46:343-345.

9. Braithwaite RS, Meltzer DO, King JT Jr, Leslie D, Roberts MS. What does the value of modern medicine say about the $\$ 50,000$ per quality-adjusted life-year decision rule? Med Care 2008:46:349-356.

10. Delbridge L, Robinson B. Genetic and biochemical screening for endocrine disease: III. Costs and logistics. World J Surg 1998;22:1212-1217.

11. Dinh TA, Rosner BI, Atwood JC, et al. Health benefits and cost-effectiveness of primary genetic screening for Lynch syndrome in the general population. Cancer Prev Res (Phila) 2011;4:9-22.

12. Grann VR, Whang W, Jacobson JS, Heitjan DF, Antman KH, Neugut Al. Benefits and costs of screening Ashkenazi Jewish women for BRCA1 and BRCA2. J Clin Oncol 1999:17:494-500.

13. Gudgeon JM, Williams JL, Burt RW, Samowitz WS, Snow GL, Williams MS. Lynch syndrome screening implementation: business analysis by a healthcare system. Am J Manag Care 2011;17:e288-e300.

14. Heimdal K, Maehle L, Møller P. Costs and benefits of diagnosing familial breast cancer. Dis Markers 1999;15:167-173.

15. Holland ML, Huston A, Noyes K. Cost-effectiveness of testing for breast cancer susceptibility genes. Value Health 2009;12:207-216.

16. Ingles J, McGaughran J, Scuffham PA, Atherton J, Semsarian C. A costeffectiveness model of genetic testing for the evaluation of families with hypertrophic cardiomyopathy. Heart 2012;98:625-630.

17. Kievit W, de Bruin JH, Adang EM, et al. Cost effectiveness of a new strategy to identify HNPCC patients. Gut 2005;54:97-102.

18. Kwon JS, Daniels MS, Sun CC, Lu KH. Preventing future cancers by testing women with ovarian cancer for BRCA mutations. J Clin Oncol 2010;28:675-682.

19. Kwon JS, Gutierrez-Barrera AM, Young D, et al. Expanding the criteria for BRCA mutation testing in breast cancer survivors. J Clin Oncol 2010;28:4214-4220.

20. Kwon JS, Scott JL, Gilks CB, Daniels MS, Sun CC, Lu KH. Testing women with endometrial cancer to detect Lynch syndrome. J Clin Oncol 2011;29:2247-2252.

21. Ladabaum U, Wang G, Terdiman J, et al. Strategies to identify the Lynch syndrome among patients with colorectal cancer: a cost-effectiveness analysis. Ann Intern Med 2011;155:69-79.

22. Marks D, Wonderling D, Thorogood M, Lambert H, Humphries SE, Neil HA. Screening for hypercholesterolaemia versus case finding for familial hypercholesterolaemia: a systematic review and cost-effectiveness analysis. Health Technol Assess 2000;4:1-123.

23. Marks D, Wonderling D, Thorogood M, Lambert H, Humphries SE, Neil HA. Cost effectiveness analysis of different approaches of screening for familial hypercholesterolaemia. BMJ 2002;324:1303.

24. Mvundura M, Grosse SD, Hampel H, Palomaki GE. The cost-effectiveness of genetic testing strategies for Lynch syndrome among newly diagnosed patients with colorectal cancer. Genet Med 2010;12:93-104.

25. Nherera L, Marks D, Minhas R, Thorogood M, Humphries SE. Probabilistic costeffectiveness analysis of cascade screening for familial hypercholesterolaemia using alternative diagnostic and identification strategies. Heart 2011;97: $1175-1181$.

26. Nielsen M, Hes FJ, Vasen HF, van den Hout WB. Cost-utility analysis of genetic screening in families of patients with germline MUTYH mutations. BMC Med Genet 2007;8:42.

27. Olsen KR, Bojesen SE, Gerdes AM, Lindorff-Larsen K, Bernstein IT. Costeffectiveness of surveillance programs for families at high and moderate risk of hereditary non-polyposis colorectal cancer. Int J Technol Assess Health Care 2007;23:89-95.

28. Perez MV, Kumarasamy NA, Owens DK, Wang PJ, Hlatky MA. Cost-effectiveness of genetic testing in family members of patients with long-QT syndrome. Circ Cardiovasc Qual Outcomes 2011;4:76-84.

29. Phillips KA, Ackerman MJ, Sakowski J, Berul Cl. Cost-effectiveness analysis of genetic testing for familial long QT syndrome in symptomatic index cases. Heart Rhythm 2005;2:1294-1300.

30. Ramsey SD, Clarke L, Etzioni R, Higashi M, Berry K, Urban N. Cost-effectiveness of microsatellite instability screening as a method for detecting hereditary nonpolyposis colorectal cancer. Ann Intern Med 2001;135(8 Pt 1): 577-588.

31. Resnick K, Straughn JM Jr, Backes F, Hampel H, Matthews KS, Cohn DE. Lynch syndrome screening strategies among newly diagnosed endometrial cancer patients. Obstet Gynecol 2009;114:530-536.

32. Reyes CM, Allen BA, Terdiman JP, Wilson LS. Comparison of selection strategies for genetic testing of patients with hereditary nonpolyposis colorectal carcinoma: effectiveness and cost-effectiveness. Cancer 2002;95: 1848-1856.

33. Rubinstein WS, Jiang H, Dellefave L, Rademaker AW. Cost-effectiveness of population-based BRCA1/2 testing and ovarian cancer prevention for Ashkenazi Jews: a call for dialogue. Genet Med 2009;11:629-639.

34. Sharma P, Boyers D, Boachie C, et al. Elucigene FH2O and LIPOchip for the diagnosis of familial hypercholesterolaemia: a systematic review and economic evaluation. Health Technol Assess 2012;16:1-266.

35. Wang G, Kuppermann M, Kim B, Phillips KA, Ladabaum U. Influence of patient preferences on the cost-effectiveness of screening for Lynch syndrome. Am J Manag Care 2012;18:e179-e185.

36. Wang VW, Koh PK, Chow WL, Lim JF. Predictive genetic testing of first degree relatives of mutation carriers is a cost-effective strategy in preventing hereditary non-polyposis colorectal cancer in Singapore. Fam Cancer 2012;11:279-289.

37. Wonderling D, Umans-Eckenhausen MA, Marks D, Defesche JC, Kastelein JJ, Thorogood M. Cost-effectiveness analysis of the genetic screening program for familial hypercholesterolemia in The Netherlands. Semin Vasc Med 2004;4: 97-104.

38. Wordsworth S, Leal J, Blair E, et al. DNA testing for hypertrophic cardiomyopathy: a cost-effectiveness model. Eur Heart J 2010;31:926-935.

39. Sie AS, Mensenkamp AR, Adang EM, Ligtenberg MJ, Hoogerbrugge N. Fourfold increased detection of Lynch syndrome by raising age limit for tumour genetic testing from 50 to 70 years is cost-effective. Ann Oncol 2014;25:2001-2007.

40. Snowsill T, Huxley N, Hoyle M, et al. A systematic review and economic evaluation of diagnostic strategies for Lynch syndrome. Health Technol Assess 2014;18:1-406.

41. Ademi Z, Watts GF, Pang J, et al. Cascade screening based on genetic testing is cost-effective: evidence for the implementation of models of care for familial hypercholesterolemia. J Clin Lipido/ 2014;8:390-400.

42. Bennette CS, Gallego CJ, Burke W, Jarvik GP, Veenstra DL. The cost-effectiveness of returning incidental findings from next-generation genomic sequencing. Genet Med; e-pub ahead of print 13 November 2014.

43. Phillips KA, Ladabaum U, Pletcher MJ, Marshall DA, Douglas MP. Key emerging themes for assessing the cost-effectiveness of reporting incidental findings. Genet Med 2015;17:314-315. 